\title{
Investigation on Quality Conformance: A Case Study on Electrical and Electronic SME Industries in Malaysia
}

\author{
Farhad Nejadi, Ezutah Udoncy Olugu and Salwa Hanim Abdul-Rashid \\ Centre for Product Design and Manufacturing, Department of Mechanical Engineering, Faculty of \\ Engineering, University of Malaya, Kuala Lumpur, Malaysia
}

Correspondence should be addressed to: Farhad Nejadi; nejadi.farhad@gmail.com

Received date: 12 October 2015; Accepted date: 31 December 2015; Published date: 15 June 2016

Academic Editor: Joriah Muhammad

Copyright ( 2016. Farhad Nejadi, Ezutah Udoncy Olugu and Salwa Hanim Abdul-Rashid. Distributed under Creative Commons CC-BY 4.0

\begin{abstract}
The level of quality management implementation is defined based on the enterprises' vision for the future. Since today's electrical and electronic industries are supposed to have high-tech enterprises, it is sensible to periodically assess them in terms of level of quality management through empirical studies. There is hardly any study that extensively investigates the relevant factors which contribute into quality conformance level in electrical and electronic industries. Also there is no study that investigates the differences and similarities between electrical industry and electronic industry in terms of obstacles of implementation. Seven hypotheses are generated based on extensive literature review in order to intensively analyze the impacts of firm's size, ISO certification standards and length of quality management maturity on quality conformance comprehensively. The data were collected from 187 small and medium size electrical and electronic industries in Malaysia. This empirical study has been conducted using online survey methodology. This study illustrates the results of statistical techniques which are used in order to investigate the correlations and interaction of contributed factors into quality conformance, investigation of the purpose of quality management implementation and comparison of obstacles between electrical and electronic industries in Malaysia. Findings of this study emphasized that ISO certification standards and adoption of quality maturity practices can significantly affect the quality conformance. It is noticeably stressed that the low to moderate response rate of responses and restricted access to numeric data related to quality conformance can be considered as limitations of this study.
\end{abstract}

Keywords: Quality conformance; SMEs; ISO; Obstacles.

Cite this Article as: Farhad Nejadi, Ezutah Udoncy Olugu and Salwa Hanim Abdul-Rashid (2016),

"Investigation on Quality Conformance: A Case Study on Electrical and Electronic SME Industries in Malaysia", Journal of Innovation Management in Small and Medium Enterprise, Vol. 2016 (2016), Article ID 725886, DOI: $10.5171 / 2016.725886$ 


\section{Introduction}

Many organizations have implemented QM principles for quality improvement. Quality management improves competitiveness as

well as productivity and reduces negative impacts of challenges (Yamada et al, 2013). Currently, many enterprises struggle to compete for the global business market status (Fekete, \& Bocskei, 2011). Thus, it is always one of the critical challenging decisions for manufacturing managers to employ efficient quality initiators towards attaining organizational excellence.

One of the thrusts impacted to competitiveness is ASEAN Free Trade Agreement (AFTA). Ahmad et al., (2014) stated that globalization, capital movement and trade liberalization within the framework of AFTA have led to extremely challenging environment for Malaysian organizations to compete in open markets. They observed that AFTA circumstance is not favorable news for local industries, which has less competitive advantage subsidizing in business in contrast with overseas enterprises. SMEs' today need to learn how to interconnect customers along with their expectations (Ošenieks \& Babauska, 2014). To overcome this, some organizations utilize improvement process through the ISO certification link to the TQM framework to ensure quality and enhancement of the process (Lai \& Cheng, 2003). In Malaysia, the level of quality in process and performance of electrical and electronic industries has been measured and observed to be lower than expected to attain the high tech enterprises view of 2020 (Best \& Rasiah, 2003; Idris et al., 1996). Also, some studies investigate quality management practices in electrical and electronic industries (Agus, 2005), Malaysian organizations (Eng \& Yusof, 2003; Ismail et al., 1998), size of organization (Price \& Chen, 1993), years of adoption (Ahire, 1996) but there is a few empirical studies conducted on electrical and electronic industries in Malaysia stated by Abdullah et al. (2008). In addition there is no study that comprehensively examines all possible variables affecting performance, their correlations and interactions.

This study supports understanding to what extent factors such as size of organization, ISO certification standards and adoption of quality maturity contribute into their performance achievement throughout TQM framework. It is believed that the outcomes of the study would effectively help electrical and electronic enterprises especially local organizations in their efforts to be ahead and be sustaining at a competitive level in the market in the future. It might be helpful to Malaysian SMEs to survive from the negative impacts of AFTA and attain the high-tech level in 2020.

\section{Literature review}

The reasons for selecting quality conformance as the main extent in this study are: It is measureable as cited in some TQM empirical studies (Arumugam et al., 2008; Prajogo \& Sohal, 2006; Yang, 2006; Ahire et al., 1996; Flynn et al., 1994). Another reason is that, quality performance is used as a measure in MBNQA model as quality result. World-wide many researchers accepted MBNQA model which represents TQM practices (Prajogo \& Sohal, 2004; Dean \& Bowen, 1994). Finally, measuring through quality conformance is strongly stressed by experts in content validity of questionnaire. Since there is the fact that ISO standards has similarity in terms of structure as well as dissemination processes (Corbett \& Kirsch, 2001; Corbett, 2006; Marimón, et al., 2006; Molina-Azorín, et al, 2009), it is sensible to jointly analyses the effects of ISO 9001, ISO 14001 and ISO 27001 on quality conformance indicated by industry experts in this study.

Based on extensive literature review, it is found that in different industries and regions of the world, different obstacles arise. Jun et al. (2004), Kaynak (2003) and Whalen \& Rahim (1994) believed that even though top management support is crucial, the lack of leadership engagement as well as shortage of proper training definitely leads organization to unsuccessful status in QM program. In 
addition to this concern, Yamada et al. (2013) stated that plentiful bureaucracy of implementation in Brazil can result into failure of QM implementations. However, in addition to top management leadership and proper training, Tari \& sabater (2004) observed that lack of knowledge about quality tools and practices is an essential issue to consider in QM implementation in Spain. Masters (1996) listed a wide range of barriers which if properly managed can lead to TQM success. He listed the barriers as: Lack of management commitment, weak comprehension of quality management, inability to change organizational cultures, lack of quality planning, lack of training and lack of resources. Adebanjo \& Kehoe (1998) stated that QM obstacles can be seen as a quality culture in implementing QM progress. The following obstacles is provided by Adebanjo \& Kehoe (1998) which concentrate on communicational issues and cultural matters; Lack of measurement system, lack of training to enhance employees' skills involving quality improvement activities, lack of communication with customer, lack of supplier involvement and lack of teamwork. Considering studies conducted in Malaysia, Ooi et al. (2012) figured out that culture of organizations can be a critical issue in TQM implementation of Malaysia's manufacturing organizations.

\section{Methodology}

The data of this study were collected through online survey sending via email. The electrical and electronic SMEs in Malaysia were considered as target population. The construction of this survey was generated after extensive literature review and conducting some field interviews with experts in electrical and electronic industries in Malaysia in order to testify the impacts of firm's size, ISO certification standards and length of quality management maturity on quality conformance. It was emphasized by experts that ISO 9001, ISO 14001 and ISO 27001 have been agreed to be effective on quality conformance in this particular industry. Prior to data analyses, factors such as reliability, validity and normality of the entire data and variables must be strictly examined (Landau \& Everitt, 2004). The next section will therefore attempt to ascertain the validity, reliability, etc of the study.

\section{Content validity, response rate, Reliability and Construct validity}

After developing the survey, a pilot study was conducted to assess the content validity. For this purpose, 15 questionnaires were distributed to academician and industry experts. The response rate of $40 \%$ was achieved. Hence, it is believed that content validity was achieved. The total number of 872 small and medium size (SMEs) electrical and electronic companies involved in export trading was selected from the Federation of Malaysia Manufacturing (FMM) website of company listing. The online survey was developed based on literature review and was sent to the companies through emails. At first, 135 responses were received. For the purpose of improving the response rate, reminder follow up emails were sent to companies. By this action, the number of respondents increased to 187 . In total, the response rate of $21.44 \%$ was obtained. In comparison with the response rate obtained in studies by the scope of Malaysia, Jusoh et al. (2008) achieved 12.3\%, Ahmed et al. (2004) obtained 9.1\% and Ahmed \& Hassan (2003) achieved 12.3\%. Jusoh et al. (2008) stressed that low response rate is not wondering in Malaysia for postal surveys. Therefore, it is believed that $21.44 \%$ is sufficiently enough to start analysis of the data. To ensure the reliability of survey instrument, Cronbach's alpha is utilized to assess and evaluate the reliability by using SPSS 20. Any item which is lower than 0.7 must be dropped. Through the analysis conducted on CSFs of implementation, Cronbach value of $0.799,0.743,0.835$ and 0.853 were obtained for CSFs in these industries and obstacles in electrical and electronic industries respectively. These values are higher than 0.7 which is a critical value. Thus, no item is deleted. For the purpose of validity test, Kaiser-Meyer-Olkin (KMO) measurement of sampling adequacy (KMO) test was performed. The value of $0.639,0.577,0.652$ and 0.562 were obtained for electrical and electronic industries

Farhad Nejadi, Ezutah Udoncy Olugu and Salwa Hanim Abdul-Rashid (2016), Journal of Innovation Management in Small and Medium Enterprise, DOI: 10.5171/2016. 725886 
respectively. KMO values more than 0.5 shows that the survey is valid.

\section{Normality test}

Normality test was conducted to ascertain whether the data are based on normal distribution. The parametric tests must be conducted on normal data and nonparametric tests run on non-normal data (Landau \& Everitt, 2004). Thus, the following hypothesis is generated.

H1: The data are normally distributed.

Normality test is conducted on all the data variables collected through survey. Since the sample size is less than 2000, the ShapiroWilk value is considered. Since (Sig. $<\alpha$ ), the null hypothesis (H1) is rejected and the data are not normally distributed. Therefore, the action was taken to make the data normal. Through transformation of computed variable, Lg 10 function was used. After testing the transformed data, it was observed that, the data are not normally distributed. Since the data are not normal, thus the nonparametric tests must be conducted on all the data of this study. Fig 1 demonstrates the overall research design overview based on non-parametric tests as well as comparisons.

Association of variables, \& independency verification (Pearson Chi Square \& crosstabs)
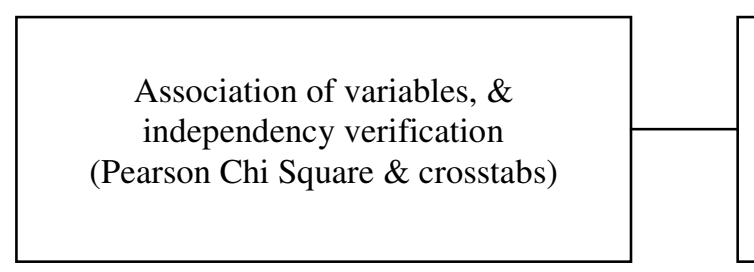

$$
\begin{aligned}
& \text { Correlation and partial correlation } \\
& \text { between independent variables } \\
& \text { and conformance } \\
& \text { (Spearman) }
\end{aligned}
$$

Estimate \& pairwise comparison (confidence interval), drawing plot of performance vs. variables
Interaction of independent

variables on performance and extent of impacts

(Factorial design $\mathrm{F}$ test)

\section{Figure 1: Non-parametric tests \& comparisons}

\section{Results and discussion}

Data collected and assessed form several hypotheses and series of statistical tests using SPSS 20.

\section{Association of variables in electrical and electronic industries}

Success rate, ISO, Size, Type of industry and adoption length are defined as categorical variable in this study. The most common method to summarize two categorical observations is drawing and analyzing Contingency tables (Landau \& Everitt, 2004). To test hypotheses related to association between factors, the Pearson-Chi square and crosstabs were performed.
H2a: There is no evidence of association between size categories and type of industry.

$H 2 b$ : There is no evidence of association between adoption categories and type of industry.

H2c: There is no evidence of association between ISO certification categories and type of industry.

H2d: There is no evidence of association between performance success categories and type of industry.

The Pearson Chi-Square calculated values are $0.198,0.168,0.930$ and 0.688 (2-tailed) 
respectively, so the null hypothesis (H2) is accepted. Thus, there is no prior possible group difference between electrical and electronic industries as samples of study in terms of size of organization, adoption categories, ISO certification categories and performance success categories. Therefore it is believed that, these variables are independent in this study.

\section{Data analysis of performance success rate}

As the categorical variables in this study are independent variables, it is therefore sensible to find out whether categorical variables predict performance success or not in electrical and electronic industries. In other words, it was analyzed that performance success is related to other categorical variables in this study. So the hypotheses generated are as follows:

H3: There is no evidence of significant correlation between quality performance success and adoption, ISO and Size in electrical and electronic industries.

For this purpose, the Spearman value must be calculated to assess whether there is any correlation between performance success and other independent variables. Since there are correlations in some extent between adoption and ISO. Landau, \& Everitt (2004) stated that when there are correlations in some extents, it is helpful to run partial correlation coefficients. It measures the strength of individual linear relationship between quality performance and other variables individually. So the hypothesis is broken down into 2 sub-hypotheses.

$H 3 a$ : There is no evidence of significant correlation between quality performance success and adoption in electrical and electronic industries.

$H 3 b$ : There is no evidence of significant correlation between performance success and ISO in electrical and electronic industries.

After run of partial correlation between performance success and adoption, and sig. < $\alpha$, so the null hypothesis $(H 3 a \& H 3 b)$ is rejected. Therefore there is a significant correlation between performance success and adoption by strength of 0.463 and 0.429 respectively. The correlation increased from 0.435 to 0.463 and from 0.410 to 0.429 after run of partial correlation for $H 3 a$ and $H 3 b$ respectively. The reason could be that part of the relationship being attributed to ISO and Size variables.

\section{Interaction of ISO and adoption on quality performance success}

To extensively analyze the effects of ISO and adoption on quality conformance success, it is needed to run factorial design. For this purpose, the hypothesis was generated to find out how the length of QM practices' adoption and ISO can affect the mean of performance success. To test the hypothesis, general linear model is performed. It is determined that length of adoption has been defined by 3 levels, while the ISO has been defined by 6 different levels.

H4: There is no evidence of interaction between adoption and ISO on performance success.

H5: The mean of quality performance success is equal between ISO certification levels.

H6: The mean of quality performance success is equal between years of adoption groups.

As shown in Table 1 , since the Sig. $=0.854>$ $\alpha$, so the null hypothesis (H10) is accepted and there is no significant interaction between adoption and ISO through affecting performance success. Similarly, since Sig. $<\alpha$, thus it implies that the mean of performance success differs between the levels of ISO certification. Likewise, since Sig. $<\alpha$, thus it implies that the mean of performance success differs based on the length of QM practices' implementation. Therefore, the pairwise comparison is needed for variables of ISO and years of QM practices adoption to analyze how the mean of conformance success differs between individual levels. 


\section{Estimation of success rate through ISO certification}

Even though p-value is important to identify major effects, it is generally advised to quantify the effects through constructing confidence intervals (Landau, \& Everitt, 2004). As the ISO has significant effects on conformance success and there is no interaction, it is sensible to estimate the differences in the mean of conformance success among ISO certification levels. It is noticeable that SPSS only offers comparison between levels where there is no interaction. In other words, only factors that do not have interaction with each other must be used (Landau, \& Everitt, 2004).

Based on the estimates of success through ISO, the highest mean is obtained by the category of all ISO levels by the mean of 4 . The lowest mean conformance success is obtained by non-ISO certification companies by the mean of 2.580. It is clear that, through attaining ISO certifications the mean of quality performance success improves from 2.580 to 4 .

According to Pairwise Comparisons of success and ISO, as comparison of non-ISO certification level with other levels, it is clearly seen that the mean difference is negative. It means categories of certification companies have higher mean of performance success. As Sig. $<\alpha$, thus all these differences are significant. As comparison of ISO 9001 to other levels, as Sig. $<\alpha$, all the differences are significant. To compare the organizations which are certificated by ISO 9001 \& 14001 with other levels, the difference is significant with non-ISO and ISO 9001 certification but there is no evidence of significant differences to organizations which additionally obtained ISO 27001 certificate.

Table 1: Tests of Between-Subjects Effects

\begin{tabular}{|l|c|c|c|c|c|}
\hline \multicolumn{7}{|c|}{ Dependent Variable: Success Rate } \\
\hline Cource & $\begin{array}{c}\text { Type III Sum of } \\
\text { Squares }\end{array}$ & Df & $\begin{array}{c}\text { Mean } \\
\text { Square }\end{array}$ & F & Sig. \\
\hline Corrected Model & 32.166 & 7 & 4.595 & 9.645 & .000 \\
\hline Intercept & 512.758 & 1 & 512.758 & 1076.283 & .000 \\
\hline ISO & 10.560 & 3 & 3.520 & 7.388 & .000 \\
\hline HL & 7.993 & 2 & 3.996 & 8.389 & .000 \\
\hline ISO * HL & .151 & 2 & .075 & .158 & .854 \\
\hline Error & 85.278 & 179 & .476 & & \\
\hline Total & 1449.000 & 187 & & & \\
\hline Corrected Total & 117.444 & 186 & & & \\
\hline
\end{tabular}

\section{Estimation of success rate through adoption years}

Since the length of adoption has significant effects on conformance success and there is

Table 2: Estimates of success through adoption

\begin{tabular}{|l|l|l|l|l|}
\hline \multicolumn{4}{|c|}{ Dependent Variable: Success Rate } \\
\hline \multirow{2}{*}{ Adoption length } & \multirow{2}{*}{ Mean } & Std. Error & \multicolumn{3}{|c|}{$95 \%$ Confidence Interval } \\
\cline { 3 - 4 } & & & Lower Bound & Upper Bound \\
\hline
\end{tabular}




\begin{tabular}{|l|l|l|l|l|}
\hline$<5$ & 2.405 & .081 & 2.244 & 2.566 \\
\hline $5-10$ & 2.775 & .104 & 2.570 & 2.981 \\
\hline$>10$ & 3.461 & .133 & 3.197 & 3.724 \\
\hline
\end{tabular}

The mean of performance success increased from 2.405 to 3.461 through the increase in the length of implementation within levels. The organizations by implementation of quality tools and practices less than 5 years obtained the mean of 2.405. It is increased to 2.775 and 3.461 for organizations which implemented quality management for 5 to 10 years and up to 10 years respectively.
Based on pairwise of success and adoption, for the category of less than 5 years QM adoption, the mean difference is significant (Sig. $<\alpha)$ and negative in comparison with other levels. For the category of 5 to 10 years, the Sig. $<\alpha$. and the mean performance success for the organization with more than 10 years implementation is more.

Table 3: Pairwise Comparisons of success and adoption

\begin{tabular}{|c|c|c|c|c|c|c|c|}
\hline \multicolumn{8}{|c|}{ Dependent Variable: Success Rate } \\
\hline & \multirow[t]{2}{*}{ How } & \multirow{2}{*}{ (J) How Long } & \multirow{2}{*}{$\begin{array}{l}\text { Mean Difference } \\
(\mathrm{I}-\mathrm{J})\end{array}$} & \multirow{2}{*}{ Std. Error } & \multirow{2}{*}{ Sig. ${ }^{d}$} & \multicolumn{2}{|c|}{$\begin{array}{l}95 \% \\
\text { Interval for Difference }\end{array}$} \\
\hline & & & & & & $\begin{array}{l}\text { Lower } \\
\text { Bound }\end{array}$ & $\begin{array}{l}\text { Upper } \\
\text { Bound }\end{array}$ \\
\hline \multirow{2}{*}{$<5$} & & $5-10$ & $-.370^{*}, \mathrm{~b}, \mathrm{c}$ & .132 & .006 & -.631 & -.109 \\
\hline & & $>10$ & $-1.056^{*}, \mathrm{~b}$ & .156 & .000 & -1.364 & -.747 \\
\hline \multirow{2}{*}{\multicolumn{2}{|c|}{$5-10$}} & $<5$ & $.370^{*}, \mathrm{~b}, \mathrm{c}$ & .132 & .006 & .109 & .631 \\
\hline & & $>10$ & $-.685^{*}, \mathrm{~b}$ & .169 & .000 & -1.019 & -.351 \\
\hline \multirow{2}{*}{\multicolumn{2}{|c|}{$>10$}} & $<5$ & $1.056^{*}, \mathrm{c}$ & .156 & .000 & .747 & 1.364 \\
\hline & & $5-10$ & $.685^{*, c}$ & .169 & .000 & .351 & 1.019 \\
\hline
\end{tabular}

Based on estimated marginal means

*. The mean difference is significant at the .05 level.

b. An estimate of the modified population marginal mean (I).

c. An estimate of the modified population marginal mean (J).

d. Adjustment for multiple comparisons: Least Significant Difference (equivalent to no adjustments)

Fig 2 demonstrated a visual result. Through considering the plot, there is significant differences of performance success mean between non-ISO and ISO 9001 certification. Through years of QM practices implementation, performance success increased significantly for both ISO and NonISO certification groups. The lines are almost parallel through less than 5 years and 5 to 10 years of QM implementation. The lines get non-parallel through period of 5 to 10 years to up to 10 years. It seems that when QM adoption approaches up to 10 years, the difference of performance success reduces but the difference level is still significant. 


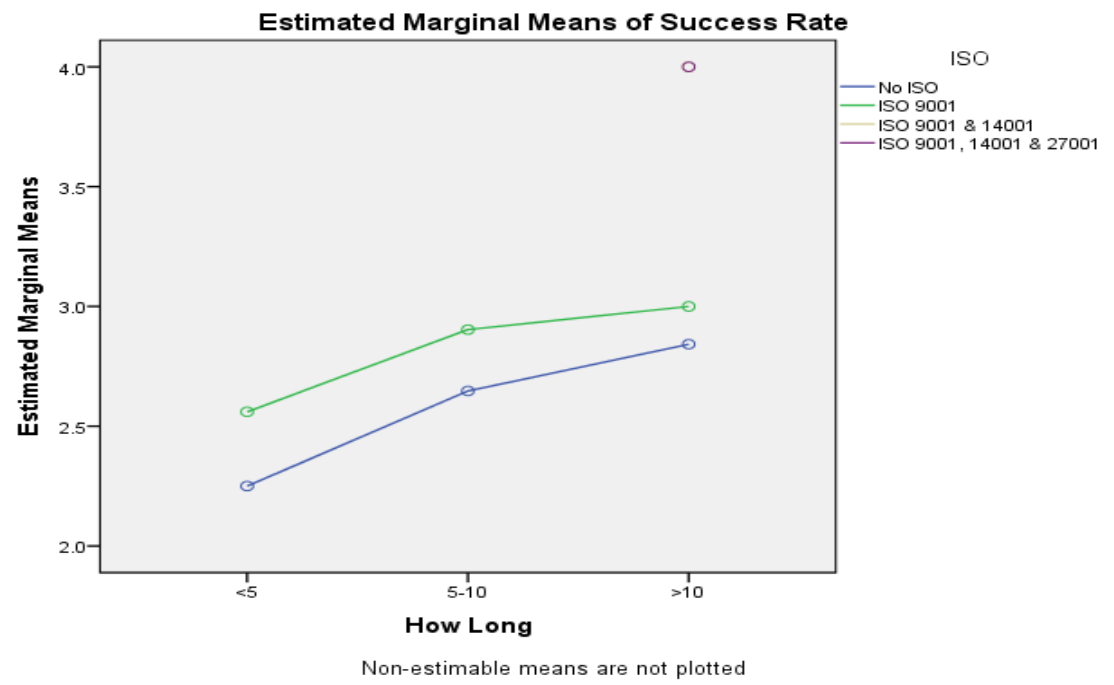

Figure 2: Plot of success rate, ISO and adoption

\section{Comparison of QM implementation obstacles}

According to Table 4, the most effective problems faced by electrical industry is culture of being reluctant to change, lack of supervision skill and lack of communication. In electronic industry, the problem faced is indicated as culture, lack of knowledge about the tools, lack of supervision skill and lack of actual supports, commitment of top management.

Table 4: Statistic of QM practices implantation's obstacles

\begin{tabular}{|l|c|c|c|c|c|c|}
\hline & \multicolumn{2}{|c|}{ Electrical, N=103 } & \multicolumn{2}{c|}{ Electronic, N=84 } & \multicolumn{2}{c|}{$\alpha=0.05$} \\
\hline Obstacles & Mean & STD & Mean & STD & $\begin{array}{c}\text { P-Value } \\
\text { (2-tailed) }\end{array}$ & $\begin{array}{c}\text { Significant } \\
\text { difference }\end{array}$ \\
\hline $\begin{array}{l}\text { Bureaucracy through } \\
\text { implementation }\end{array}$ & 3.39 & .983 & 3.44 & 1.022 & .639 & No \\
\hline $\begin{array}{l}\text { Lack of knowledge about } \\
\text { benefit of tools }\end{array}$ & 3.79 & .824 & 4.05 & .558 & .004 & Yes \\
\hline Lack of supervision skill & 3.94 & .654 & 3.88 & .609 & .715 & No \\
\hline Lack of reward system & 3.50 & .712 & 3.67 & .700 & .126 & No \\
\hline $\begin{array}{l}\text { Culture (Being reluctant to } \\
\text { change) }\end{array}$ & 4.04 & .713 & 4.08 & .732 & 0.496 & No \\
\hline $\begin{array}{l}\text { Cost of consultancies and } \\
\text { training }\end{array}$ & 3.59 & .747 & 3.74 & .661 & 0.158 & No \\
\hline Lack of time & 3.55 & .696 & 3.68 & .697 & 0.171 & No \\
\hline
\end{tabular}




\begin{tabular}{|l|c|c|c|c|c|c|}
\hline $\begin{array}{l}\text { Lack of actual commitment } \\
\text { of top management }\end{array}$ & 3.83 & .747 & 3.80 & .773 & 0.997 & No \\
\hline Lack of communication & 3.94 & .683 & 3.71 & .815 & .096 & Yes \\
\hline Poor measurement system & 3.81 & .687 & 3.73 & .750 & 0.715 & No \\
\hline Lack of quality system & 3.80 & .677 & 3.74 & .696 & 0.604 & No \\
\hline $\begin{array}{l}\text { Lack of actual } \\
\text { empowerment }\end{array}$ & 3.71 & .620 & 3.60 & .661 & 0.252 & No \\
\hline
\end{tabular}

Since the mean rank compares difference in both industries, it would be sensible to investigate whether there is any evidence of significant differences in the average mean of obstacles between electrical and electronic industries.

H7: There is no evidence of obstacles mean differences between electrical industry and electronic industry.

To assess this hypothesis, as the data distribution is not normal, the Wilcoxon signed rank test for non-parametric data analysis was performed to find out whether there is any significant evidence of differences for each individual obstacle between the two industries. For extensive analysis, $\mathrm{H} 7$ was examined through all 12 obstacles individually. Based on table 4 , the Sig. $>2 \alpha$ for lack of knowledge about benefit of tools and lack of communication, thus for these 2 practices categories, the null hypothesis (H7) is rejected. Therefore, the mean differences for these 2 obstacles are significant from each other in electrical and electronic industries.

\section{Conclusion}

The data gathered from the sample of 187 SMEs out of 872 electrical and electronics companies in Malaysia which are active in export were testified through several hypotheses and series of statistical analyses using SPSS 20 and summarized as follows. It was found that $52.4 \%$, the majority of organizations implemented quality management practices up to 5 years maturity. While $53.5 \%$ of organizations have not been certificated by any type of ISO. The result showed, $61.5 \%$ of companies in Malaysia indicated themselves as successful and very successful in terms of quality performance. In this study it was extensively testified that independent factors such as ISO, size of organization and length of quality management practices' adoption predict performance success rate. It was found that ISO certification standards and levels of quality management implementations individually affect performance success rate. The result showed that there is no evidence of significant interaction between ISO certification standards and years of quality management implementation on performance success rate. It was clearly demonstrated that through the increase in years of adoption in organizations of up to 10 years, performance success rate increased significantly. It was also clear that being certified by a type of ISO standards can lead to very successful quality performance level. Overall, it was found that there is a significant difference between non-ISO and ISO 9001 certificated organizations before 10 years of quality management practices implementation. Among obstacles, the result showed that there are significant differences between electrical industry and electronic industry in terms of lack of knowledge about benefit of tools and lack of communication. This study is unique due to the fact that it considered almost all variables contributing to success comprehensively.

\section{Acknowledgment}

Authors wish to express gratitude to University of Malaya for funding the research (Grant no. RP018C-13AE

\section{References}

1. Abdullah, M. M. B., Ahmad, Z. A., \& Ismail, A. (2008). The Importance of Soft Factors for 
Quality Improvement: Case Study of Electrical and Electronics Firms in Malaysia. International Journal of Business and Management, 3(12), P60.

2. Adebanjo, D., \& Kehoe, D. (1998). An Evaluation of Quality Culture Problems in UK Companies. International Journal of Quality Science, 3(3), 275-286.

3. Agus, A. (2005). The Structural Linkages between TQM, Product Quality Performance, and Business Performance: Preliminary Empirical Study in Electronics Companies. Singapore Management Review, 27(1), 87-105.

4. Ahire, S. L. (1996). TQM Age versus Quality: An Empirical Investigation. Production and Inventory Management Journal, 37, 18-23.

5. Ahmad, M. F., Zakuan, N., Jusoh, A., Yusof, S. M., \& Takala, J. (2014). Moderating Effect of ASEAN Free Trade Agreement between Total Quality Management and Business Performance. Procedia-Social and Behavioral Sciences, 129, 244-249.

6. Ahmed, S., \& Hassan, M. (2003). Survey and Case Investigations on Application of Quality Management Tools and Techniques in SMEs. International Journal of Quality \& Reliability Management, 20(7), 795-826.

7. Ahmed, S., Hassan, M. H., \& Taha, Z. (2004). State of Implementation of TPM in SMEs: A Survey Study in Malaysia. Journal of Quality in Maintenance Engineering, 10(2), 93-106.

8. Arumugam, V., Ooi, K. B., \& Fong, T. C. (2008). TQM Practices and Quality Management Performance: An Investigation of Their Relationship Using Data from ISO 9001: 2000 Firms in Malaysia. The TQM Journal, 20(6), 636-650.

9. Best, M. H., \& Rasiah, R. (2003). Malaysian Electronics: At the Crossroads. UNIDO, Programme Development and Technical Cooperation Division.
10. Corbett, C.J., \& Kirsch, D.A. (2001). International Diffusion of ISO 14000 Certification. Production and Operations Management, 10, 327-42.

11. Corbett, C.J. (2006). Global Diffusion of ISO 9000 Certification through Supply Chains. Manufacturing and Service Operations Management, 8, 330-50.

12. Dean, J. W., \& Bowen, D. E. (1994). Management Theory and Total Quality: Improving Research and Practice through Theory Development. Academy of Management Review, 19(3), 392-418.

13. Eng, Q. E., \& Yusof, S. R. M. (2003). A Survey of TQM Practices in the Malaysian Electrical and Electronic Industry. Total Quality Management and Business Excellence, 14, 63-78.

14. Fekete, H., \& Bocskei, E. (2011). Cultural Waves in Company Performance. Research Journal of Economics, Business and ICT, 3.

15. Idris, M. A., Mcewan, W., \& Belavendram, N. (1996). The Adoption of ISO 9000 and Total Quality Management in Malaysia. The TQM Magazine, 8(5), 65-68.

16. Ismail, M. Y., Baradie, M. E., \& Hashmi, M. S. J. (1998). Quality Management in the Manufacturing Industry: Practice vs. Performance. Computers and Industrial Engineering, 35(3), 519-522.

17. Jun, M., Cai, S., \& Peterson, R. (2004). Obstacles to TQM implementation in Mexico's Maquiladora industry. Total Quality Management \& Business Excellence, 15(1), 59-72.

18. Jusoh, R., Ibrahim, D. N., \& Zainuddin, Y. (2008). The Performance Consequence of Multiple Performance Measures Usage: Evidence from the Malaysian Manufacturers. International Journal of Productivity and Performance Management, 57(2), 119-136. 
19. Kaynak, H. (2003). The Relationship between Total Quality Management Practices and Their Effects on Firm Performance. Journal of Operations Management, 21(4), 405-435.

20. Lai, K. H., \& Cheng, T. C. E. (2003). Initiatives and Outcomes of Quality Management Implementation across Industries. Omega, 31(2), 141-154.

21. Landau, S., \& Everitt, B. (2004). A Handbook of Statistical Analyses Using SPSS (Vol. 1). Boca Raton, FL: Chapman and Hall/CRC.

22. Marimón, F., Casadesús, M., \& Heras, I. (2006). ISO 9000 and ISO 14000 Standards: An International Diffusion Model. International Journal of Operations and Production Management, 26, 141-65.

23. Molina-Azorín, J.F., Tarí, J.J., ClaverCortés, E., \& López-Gamero, M.D. (2009). Quality Management, Environmental Management and Firm Performance: A Review of Empirical Studies and Issues of Integration. International Journal of Management Reviews, 11(2), 197- 222.

24. Masters, R. J. (1996). Overcoming the Barriers to TQM's Success. Quality Progress, 29(5), 53.

25. Ooi, K. B., Cheah, W. C., Lin, B., \& Teh, P. L. (2012). TQM Practices and Knowledge Sharing: An Empirical Study of Malaysia's Manufacturing Organizations. Asia Pacific Journal of Management, 29(1), 59-78.
26. Ošenieks, J., \& Babauska, S. (2014). The Relevance of Innovation Management as Prerequisite for Durable Existence of Small and Medium Enterprises. Procedia-Social and Behavioral Sciences, 110, 82-92.

27. Prajogo, D. I., \& Sohal, A. S. (2006). The Relationship between Organization Strategy, Total Quality Management (TQM) and Organization Performance - The Mediating Role of TQM. European Journal of Operational Research, 168(1), 35-50.

28. Price, M. J., \& Chen, E. E. (1993). Total Quality Management in a Small, HighTechnology Company. California Management Review, 35(3), 96-117.

29. Tarí, J. J., \& Sabater, V. (2004). Quality Tools and Techniques: Are They Necessary for Quality Management? International Journal of Production Economics, 92(3), 267280.

30. Whalen, M. J., \& Rahim, M. A. (1994). Common Barriers to Implementation and Development of A TQM Program. Industrial Management, 36(2), 19-21.

31. Yamada, T. T., Poltronieri, C. F., Gambi, L. D. N., \& Gerolamo, M. C. (2013). Why Does the Implementation of Quality Management Practices Fail? A Qualitative Study of Barriers in Brazilian Companies. Procedia-Social and Behavioral Sciences, 81, 366-370.

32. Yang, C. C. (2006). The Impact of Human Resource Management Practices on the Implementation of Total Quality Management: An Empirical Study on HighTech Firms. The TQM Magazine, 18(2), 162173.

Farhad Nejadi, Ezutah Udoncy Olugu and Salwa Hanim Abdul-Rashid (2016), Journal of Innovation Management in Small and Medium Enterprise, DOI: 10.5171/2016. 725886 